\title{
The impact of dosing sequence on the removal of the persistent pesticide metaldehyde using powdered activated carbon with coagulation and clarification
}

\author{
Sara Sanchez Lopez ${ }^{1}$, Jitka Macadam¹, Mark Biddle ${ }^{2}$ and Peter Jarvis ${ }^{1 *}$ \\ ${ }^{1}$ Cranfield University, Cranfield, Bedfordshire, MK43 OAL \\ ${ }^{2}$ Doosan Enpure Ltd, Doosan House Business Park, Parklands, Rubery, B45 9PZ \\ *Corresponding author: p.jarvis@cranfield.ac.uk
}

\section{Abstract}

Removal of pesticides from drinking water remains a challenge for water treatment suppliers throughout the world. A combined treatment of dissolved air flotation (DAF) and powdered activated carbon (PAC) was investigated as a treatment process for removal of the recalcitrant pesticide metaldehyde. The PAC dosing position relative to the coagulant was studied regarding its impact on the removal of NOM and pesticide, floc formation and the clarification efficiency. Four different water sources were spiked with the pesticide and treated using PAC. A PAC dose of $100 \mathrm{mg} / \mathrm{L}$ using a contact time of 20 minutes was required in order to effectively remove pesticide to the compliance concentrations for all of the water sources. The pesticide adsorption rate $\left(k_{\text {met }}\right)$ decreased as the source water DOC increased, moving from 79.5 to $21.0 \mathrm{mg} / \mu \mathrm{g} / \mathrm{min}$ with an increase in DOC from 2.6 to $6.5 \mathrm{mg} / \mathrm{L}$. When combined with coagulation, the sequence of addition of PAC followed by coagulant was most effective due to increased incorporation of PAC into the floc, large floc size (median floc size $800 \mu \mathrm{m}$ ) and a high level of pesticide removal, reducing the metaldehyde concentration to $0.18 \mu \mathrm{g} / \mathrm{L}$. Limited incorporation of PAC into flocs was observed when the adsorbent was added 
after the coagulant. The results provide a rational basis for selection of process conditions for pesticide removal using PAC and clarification.

Keywords: Clarification, floc, pesticide, adsorption, powdered activated carbon (PAC) 


\section{Introduction}

Pesticide contamination of water sources used for drinking remains a significant challenge worldwide. There are more than 5,400 pesticides regulated for use in potable water across more than 100 nations (Zijian and Jennings, 2017). Hence, the drinking water sector needs robust treatment strategies to enable effective removal of this broad grouping of chemical compounds (Cosgrove et al., 2019). For example, metaldehyde is a molluscicide pesticide that has caused significant treatment issues for water utilities in the UK over the last 10 years (Castle et al., 2017). It has been found in many water sources at concentrations exceeding EU statutory concentrations and, because of difficulties in treating the pesticide, has been occasionally detected in drinking water. The treatability of pesticides depends on their physical and chemical properties (Marshal, 2013). The traditional approach to removal of pesticides at water treatment works is through oxidation by ozone or chlorine and adsorption using granular activated carbon (GAC) (Salvestrini et al., 2016). While this has been effective for a broad range of pesticides, some pesticides are not well removed by these processes. For example, oxidation by chlorine and ozone cannot break down the molecular structure of some compounds (Marshal 2013; Kay \& Grayson 2014). GAC is not economically viable for removal of pesticides that have weak affinity for adsorption. This includes metaldehyde, where breakthrough of GAC is observed after only a few weeks (Tang et al. 2016). Metaldehyde is a relatively small molecule $(176.2 \mathrm{~g} / \mathrm{mol}$ ), with relatively low hydrophobicity (log kow 0.12 and log koc $0.18-0.37$ ) (Li et al., 2020). This means that other organic molecules of higher molecular weight and hydrophobicity are preferentially adsorbed and can cause desorption of weakly bound metaldehyde. New technologies have emerged to 
more effectively degrade recalcitrant pesticides. This includes advanced oxidation processes (AOP) that generate the highly oxidative hydroxyl radical. The most commonly used AOP combines ultraviolet light (UV) irradiation with $\mathrm{H}_{2} \mathrm{O}_{2}$ (Autin et al., 2012). However, these processes are not widely applied due to high capital and operational costs (Cosgrove et al., 2019). Other approaches have focused on application of alternative adsorbents, ion exchange and nanoparticle catalysts (Tao and Fletcher 2016; Li et al., 2017). Powdered activated carbon (PAC) has shown better removal of some pesticides when compared with GAC. This may be for a number of reasons associated with differences in the carbonaceous raw material of the sorbent and different activation procedures. In turn, this may lead to differences in adsorption sites and pore size distributions, resulting in differences in affinity for pesticides (Li et al., 2020). However, one of the other main reasons for PAC being more effective is that fresh adsorbent is continuously added to water, providing new adsorption sites for contaminants to be removed. GAC, on the other hand, is left in a filter bed and exposed to water over a period of months or even years resulting in greater opportunities for competitive interactions and desorption.

In comparison to other media, PAC has proven to be very effective for micropollutant removal. For example, Li et al. (2017) researched three nanoparticle catalysts and PAC for the removal of metaldehyde from water, reporting PAC to be the most efficient material, achieving up to $90 \%$ removal. Further research supports these results, showing effective removal of metaldehyde and emerging pollutants by PAC (Li et al., 2019, Bernal-Romero, 2019). Compared to alternatives, PAC is relatively low cost, simple to operate, 
can be dosed during seasonal water quality events and has wide-scale use in the water industry. In addition, it can be integrated into most clarification based WTWs with minimal infrastructure adaptations.

PAC is usually dosed into the contaminated water as a fine powder in a slurry (particle diameters typically smaller than $45 \mu \mathrm{m}$ ), prior to or with the coagulant. The PAC is then agglomerated into the flocs by coagulation and flocculation before being removed from the water by clarification, driven by either sedimentation or dissolved air flotation (DAF) processes. Previous researchers have indicated that sedimentation may not be an effective mechanism of clarification for flocs containing PAC due to the relatively low density of the adsorbent particles (Huang et al., 2020). Flotation was therefore investigated in this research due to the paucity of information available for application of this process in combination with PAC. While PAC is commonly dosed prior to the coagulant (Cook et al., 2001), research on the most effective dosing position of PAC for contaminant removal have given contradictory results. For example, the best removal of the fungicide dodine and lindane by PAC were obtained when the adsorbent was dosed after the coagulant at concentrations of up to $100 \mathrm{mg} / \mathrm{L}$ for at least 30 minutes (Kouras et al., 1995; Kouras et al., 1998). However in these experiments, the organic pollutants were spiked into de-ionised water at $250 \mu \mathrm{g} / \mathrm{L}$ for dodine and $10 \mu \mathrm{g} / \mathrm{L}$ for lindane, with no competing background organic compounds. Cook et al. (2001) researched PAC dosing applying PAC at least 30 min before the coagulant addition for MIB and geosmin removal for four different source waters with DOC varying from 4.2 to $10.0 \mathrm{mg} / \mathrm{L}$. PAC doses ranged from 22-55 mg/L and MIB and Geosmin concentrations of 39-45 $\mathrm{ng} / \mathrm{L}$ and 
31-37 ng/L, respectively. For three of the water sources of low to moderate turbidity (2.3-6.0 NTU), coagulation did not hinder the removal of MIB and Geosmin to below concentrations of $10 \mathrm{ng} / \mathrm{L}$. The fourth water had a high turbidity (>60 NTU) and this attributed to tighter binding of PAC in flocs, which slowed transfer of the contaminant onto the adsorbent. Other authors have tested the addition of PAC before, simultaneously and after the coagulant for removal of humic acid (3 mg/L DOC) from simulated seawater (Duan et al., 2003). The addition of PAC at a concentration of $500 \mathrm{mg} / \mathrm{L}$ one minute before the coagulant resulted in the most efficient removal of the humic acid. Li et al (2020) identified that PAC removal for metaldehyde removal was best when dosed into water that had already been flocculated, but this work did not investigate how the resultant PAC would be removed from the water. This paper therefore considers the practical consequences of changing dosing position of PAC. For example, the impacts of PAC on resultant floc structure and strength have not been widely considered. This is important missing information because breakage of flocs or release of PAC may negatively impact downstream processes. The use of PAC in water treatment therefore needs consideration of how the fine adsorbent material is most effectively removed from the water, in addition to the removal of the micropollutant target. A balance between the contaminant removal and the clarification performance therefore needs to be reached for efficient treatment. The aims of this study were to therefore understand how the dosing position of PAC influences the removal of recalcitrant pesticide and determine how PAC affects floc formation and the resultant clarification (focussing on flotation in this research). 


\section{Materials and Methods}

\subsection{Water sources}

Experiments were conducted using four different source waters: Water A (groundwater), Water B (river water), Water C (river water), and Water D (reservoir water). Water samples were collected three times during the study to account for potential variations in water quality. Water was stored at $4{ }^{\circ} \mathrm{C}$ and left to reach room temperature $\left(21 \pm 2^{\circ} \mathrm{C}\right)$ prior to experiments.

\subsection{Chemicals and reagents}

All chemicals used were of analytical grade or above. Ferric sulphate (Ferripol xl, EA, West) was used as coagulant, with $0.1 \mathrm{M} \mathrm{HCl}$ and $0.1 \mathrm{NaOH}$ (Fisher Scientific, UK), used to adjust $\mathrm{pH}$. A stock solution of metaldehyde was prepared by dissolving $10 \mathrm{mg}$ of metaldehyde (Sigma Aldrich, Germany) in $1 \mathrm{~L}$ of deionised water (DI) (15 M $\Omega$, Pure Lab Option, Elga, UK) and mixed for $36 \mathrm{~h}$. The PAC used was Norit SA-Super (Cabot, USA). The PAC had a median size of $10.9 \mu \mathrm{m}$, dry density of $250 \mathrm{~kg} / \mathrm{m}^{3}$ and iodine number of $1050 \mathrm{~g} / \mathrm{kg}$. The PAC has been reported to have a total BET specific surface (SS) area of $989 \mathrm{~m}^{2} / \mathrm{g}$ and be predominantly microporous $\left(693 \mathrm{~m}^{2} / \mathrm{g}\right)$ (Bizi, 2019). A stock solution of PAC was prepared by suspending $10 \mathrm{~g}$ of PAC (Cabot, USA) dried overnight at $105^{\circ} \mathrm{C}$, in $500 \mathrm{~mL}$ of DI water, mixed overnight. Fresh stock solutions were prepared weekly. Metaldehyde was spiked to achieve a concentration of $2 \mu \mathrm{g} / \mathrm{L}$, a typical concentration seen in environmental water sources, for all adsorption and kinetics experiments. 


\subsection{Adsorption tests}

Adsorption tests were carried out on a DAF jar tester that simulates the coagulation, flocculation and flotation process (DBT6 EC Engineering, Alberta, Canada). To investigate the required PAC dose, a range of PAC doses (0-200 $\mathrm{mg} / \mathrm{L}$ ) were added to $1 \mathrm{~L}$ of water in square jars and mixed at $100 \mathrm{rpm}$ (approximately velocity gradient, G, $180 \mathrm{~s}^{-1}$ ) for 20 min with no $\mathrm{pH}$ adjustment. To study the adsorption kinetics, $50 \mathrm{mg} / \mathrm{L}$ of PAC was dosed and $500 \mathrm{~mL}$ of water was mixed at 100 rpm over a range of different contact times (0-120 min). At the end of each experiment, samples were filtered $(0.45 \mu \mathrm{m})$ and analysed for metaldehyde concentration, dissolved organic carbon (DOC) and $U_{254 .}$

\subsection{Coagulation and clarification}

The impact of coagulation on PAC and contaminant removal was carried out on the jar tester according to the following: Ferric sulphate coagulant was added to $1 \mathrm{~L}$ of raw water followed by $1 \mathrm{~min}$ of rapid mixing (300 rpm, G of $950 \mathrm{~s}^{-1}$ ). Coagulation $\mathrm{pH}$ was adjusted to 4.5 (optimum obtained from preliminary experiments for combined removal of organic matter and turbidity). The mixing speed was then reduced to $55 \mathrm{rpm}\left(\mathrm{G}=80 \mathrm{~s}^{-1}\right)$ for $10 \mathrm{~min}$ during the slow stir period. Following floc formation, air bubbles for flotation were introduced into the water by the addition of air-saturated water (equivalent to $10 \%$ recycle) and a 10 minute clarification phase followed. In order to determine the optimum coagulation doses, coagulant doses from 4 to $9 \mathrm{mg} / \mathrm{L}$ as Fe were investigated for raw water with and without PAC $(50 \mathrm{mg} / \mathrm{L})$. Tests investigating the impact of PAC on clarification took place using PAC at concentrations of 25, 50, 100, 150, 200 $\mathrm{mg} / \mathrm{L}$. 


\subsection{Influence of dosing position on PAC and pesticide removal}

Three different experiments were conducted to study the influence of the dosing position of PAC on metaldehyde removal and clarification. A PAC dose of 100 $\mathrm{mg} / \mathrm{L}$ was used based on the optimisation experiments, with a coagulant dose of $7 \mathrm{mg} / \mathrm{L}$ as Fe. Three different dosing positions and sequences were investigated (further detail on the dosing procedures are shown in Supporting Information (SI) Figure S1): 1) PAC-Coag: PAC was rapidly dispersed at $300 \mathrm{rpm}$ followed by a 1 or 5 minute adsorbent contact time at $150 \mathrm{rpm}\left(\mathrm{G}\right.$ of $\left.450 \mathrm{~s}^{-1}\right)$. Coagulant was then added during a 1 minute rapid mix at $300 \mathrm{rpm}$. There then followed a flocculation period of 10 minutes at $55 \mathrm{rpm}$ and a flotation period of 10 minutes with no stirring; 2) Simult: PAC and coagulant were dosed simultaneously during a rapid mix period of 1 minute at $300 \mathrm{rpm}$ followed by a flocculation period of $55 \mathrm{rpm}$ and a flotation period of 10 minutes with no stirring; and 3) Coag-PAC: coagulant was dosed before PAC using a 1 minute rapid mix period at $300 \mathrm{rpm}$ followed by a 1 or 5 minute mixing period at $150 \mathrm{rpm}$. PAC was then dosed during a 1 minute rapid mix at $300 \mathrm{rpm}$. There then followed a 10 minute flocculation period at 55 rpm followed by a 10 minute flotation time.

Samples were taken from the sampling points positioned at the bottom of the jars to directly measure residual turbidity and zeta potential. Samples were then filtered $(0.45 \mu \mathrm{m})$ and analysed for metaldehyde, DOC, and $U V_{254}$. The filters were weighed after drying overnight at $105{ }^{\circ} \mathrm{C}$ before and after filtration to calculate suspended solids. 


\subsection{Floc size and strength}

Study into the effect of PAC on floc formation, breakage and regrowth was conducted using a particle sizing instrument (Mastersizer 3000, Malvern, UK). This instrument was used to monitor the floc size distributions formed during coagulation and flocculation for systems with and without PAC. $1 \mathrm{~L}$ of raw water in a cylindrical beaker was placed on a jar tester (Phipps and Bird PB-900, Virginia, USA) connected to the particle size instrument. Water was continuously pumped from the jar through the optical unit of the particle sizer and returned to the jar during the rapid mix and floc formation stage following the protocol of Jarvis et al. (2005a). Briefly, inflow and outflow tubes of $5 \mathrm{~mm}$ internal diameter were placed in the jar at a depth of approximately $2.5 \mathrm{~cm}$ from the water surface opposite one another. Water was pumped through the particle size instrument by a peristaltic pump. Floc size was measured at least every minute during the floc formation stage. Initial floc sizing experiments were carried out for the PAC dosing position and sequence strategies outlined in section 2.5. Floc size monitoring was carried out during the flocculation period, using an extended flocculation period of 20 minutes to ensure that a steady-state floc size had been reached. More detailed floc growth, breakage and re-growth tests were carried out for PAC dosing before the coagulant using five different doses of PAC $(0,25$, $50,100$, and $200 \mathrm{mg} / \mathrm{L})$. When PAC was used, it was dispersed during 2 minutes of rapid mix at $200 \mathrm{rpm}\left(127 \mathrm{~s}^{-1}\right)$. The coagulant was then added at $7 \mathrm{mg} / \mathrm{L}$ as $\mathrm{Fe}$ and the $\mathrm{pH}$ adjusted to 4.5 during another rapid mix period of 1 minute. Slow mixing (55 rpm, $18 \mathrm{~s}^{-1}$ ) was applied for 10 minutes for floc growth. The response of the flocs to increased shear rate was then assessed by increasing the stirrer speed to $200 \mathrm{rpm}$ for 10 minutes. The ability of the flocs to regrow was then 
established by re-introducing a slow stir period over $10 \mathrm{~min}$ at $55 \mathrm{rpm}$. In addition, during these experiments flocs were carefully withdrawn from the jar during the slow mixing phase of the jar test and observed under a microscope to understand how the PAC was distributed in the floc structure.

Floc strength and recoverability tests were undertaken to understand how PAC influenced the growth, breakage and re-growth of flocs. These experiments were important to help explain PAC incorporation and release during clarification. The following factors were used to establish floc strength and re-growth (Wang et al. 2011):

Strength Factor $=F 2 / F 1 \times 100$

Regrowth Factor $=$ F3/F2 $\times 100$

where $F 1$ is the median floc size before breakage, F2 is the floc size after breakage, and F3 is the size of flocs after regrowth.

\subsection{Analytical methods}

All water sources were characterised by $\mathrm{pH}$ and conductivity (Hanna Instruments, UK), UV 400 and $U_{254}$ (Spectroquant Pharo 300, Germany), turbidity (2100N Turbidimeter $\mathrm{HACH}, \mathrm{USA}$ ), zeta potential (Zeta Sizer Nano series. Malvern, UK), suspended solids (0.5L following the standard method 2450-D (APHA, 1992)), alkalinity (HCl titrimetric method 2320B, APHA, 1992), DOC (TOC-V CSH total organic carbon analyzer, Shimadzu, UK) and metaldehyde. Metaldehyde analyses were conducted using gas chromatography-mass spectrometry (GCMS) with a limit of quantification of $0.025 \mu \mathrm{g} / \mathrm{L}$. Samples for UV, DOC, alkalinity 
and metaldehyde were filtered through a $0.45 \mu \mathrm{m}$ filter (cellulose nitrate, Whatman, Germany). Residual turbidity and $\mathrm{UV}_{254}$ were used as indicators to assess bulk removal following clarification. 


\section{Results and Discussion}

Water A was a groundwater influenced by karstic geology. It therefore contained a higher background DOC concentration than would be expected for most groundwaters as a result of significant impacts from surface water $(4.9 \mathrm{mg} / \mathrm{L} \mathrm{DOC}$ and $13.2 \mathrm{abs} / \mathrm{m} \mathrm{UV}_{254}$ ) and a turbidity of $11.4 \mathrm{NTU}$. Water B was an upland river water impacted by peat soils. It therefore had a high $U_{254}(20.3 \mathrm{abs} / \mathrm{m}), \mathrm{DOC}$ (5.8 mg/L), and turbidity (11.1 NTU). Water C was a river water of high quality with a low $U_{254}(1.7 \mathrm{abs} / \mathrm{m})$, DOC (2.63 mg/L) and turbidity (2.5 NTU). Water D was a reservoir water of low turbidity (1.3 NTU) and a high DOC concentration of $6.54 \mathrm{mg} \mathrm{L}^{-1}$. Background metaldehyde was detected only in Water $\mathrm{D}$ at 0.119 $\mu \mathrm{g} / \mathrm{L}$ (Table 1). Metaldehyde was spiked into all water sources to obtain a concentration of $2 \mu \mathrm{g} / \mathrm{L}$ in all subsequent experiments.

Table 1. Water quality for the different sources used in the clarification experiments.

\begin{tabular}{|l|l|l|l|l|}
\hline & Water $\boldsymbol{A}$ & Water $\boldsymbol{B}$ & Water $\mathbf{C}$ & Water $\boldsymbol{D}$ \\
\hline pH & $7.6 \pm 0.0$ & $8.3 \pm 0.0$ & $8.6 \pm 0.0$ & $8.3 \pm 0.0$ \\
\hline Turbidity (NTU) & $11.4 \pm 1.4$ & $11.1 \pm 0.3$ & $2.5 \pm 0.2$ & $1.3 \pm 0.1$ \\
\hline $\begin{array}{l}\text { Suspended solids } \\
\text { (mg/L) }\end{array}$ & 13.6 & 16.6 & 0.8 & 0.2 \\
\hline $\mathbf{U V}_{\mathbf{2 5 4}}(\mathbf{a b s} / \mathbf{m})$ & $13.2 \pm 0.7$ & $20.3 \pm 0.2$ & $5.4 \pm 1.0$ & $13.6 \pm 0.9$ \\
\hline $\mathbf{U V}_{\mathbf{4 0 0}(\mathbf{a b s} / \mathbf{m})}$ & $1.0 \pm 1.0$ & $1.3 \pm 0.1$ & $1.7 \pm 0.2$ & $2.1 \pm 0.1$ \\
\hline DOC (mg/L) & 4.9 & 5.8 & 2.6 & 6.5 \\
\hline SUVA (L/mg.cm) & 2.7 & 3.5 & 2.1 & 2.1 \\
\hline Conductivity (mS) & $0.9 \pm 0.0$ & $0.5 \pm 0.0$ & $0.6 \pm 0.0$ & $0.7 \pm 0.0$ \\
\hline Zeta potential (mV) & $-13.3 \pm 0.9$ & $-13.6 \pm 0.2$ & $-10.7 \pm 1.1$ & $-12.2 \pm 1.1$ \\
\hline $\begin{array}{l}\text { Alkalinity } \\
\text { (mg/L as CaCO }\end{array}$ ) & $250 \pm 0$ & $163 \pm 2$ & $245 \pm 0$ & $160 \pm 0$ \\
\hline Metaldehyde $(\boldsymbol{\mu g} / \mathbf{L})$ & $<0.025$ & $<0.025$ & $<0.025$ & 0.119 \\
\hline
\end{tabular}




\subsection{PAC dosing for metaldehyde removal}

For all source waters there was an initial rapid reduction in metaldehyde (Figure 1a). After 5 minutes, for a PAC dose of $50 \mathrm{mg} / \mathrm{L}, 85.2 \%$ pesticide removal was seen from Water $\mathrm{A}, 85.5 \%$ from Water $\mathrm{B}, 92.7 \%$ from Water $\mathrm{C}$, and $80.7 \%$ from Water D. However, more extended contact times were required in order to reduce the pesticide near to the European Union permitted pesticide concentration in drinking water $(0.1 \mu \mathrm{g} / \mathrm{L})$. For example, it was only possible to reduce metaldehyde to under $0.1 \mu \mathrm{g} / \mathrm{L}$ for one water source (Water B) using a PAC dose of $50 \mathrm{mg} / \mathrm{L}$. To reliably reach concentrations below 0.1 , higher concentrations of PAC were required (Figure 1c). Using a contact time of 20 mins, a PAC dose of $100 \mathrm{mg} / \mathrm{L}$ resulted in residual metaldehyde concentrations of $0.05 \mu \mathrm{g} / \mathrm{L}$ for all the waters (Figure 1c). In the case of DOC, most removal was also seen in the first five minutes of contact time, with $31.9 \%$ removal seen for Water $\mathrm{A}, 28.6 \%$ from Water B, 24.1\% from Water C, and $30.1 \%$ from water D (Figure $1 \mathrm{~b}$ ). Increasing PAC dose resulted in improved DOC removal, with levels plateauing as the concentration increased above $100 \mathrm{mg} / \mathrm{L}$ (Figure 1d). 


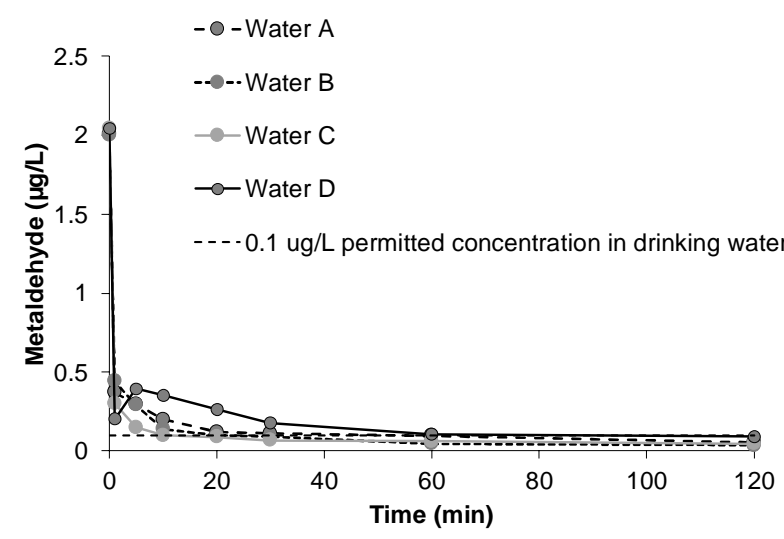

a.

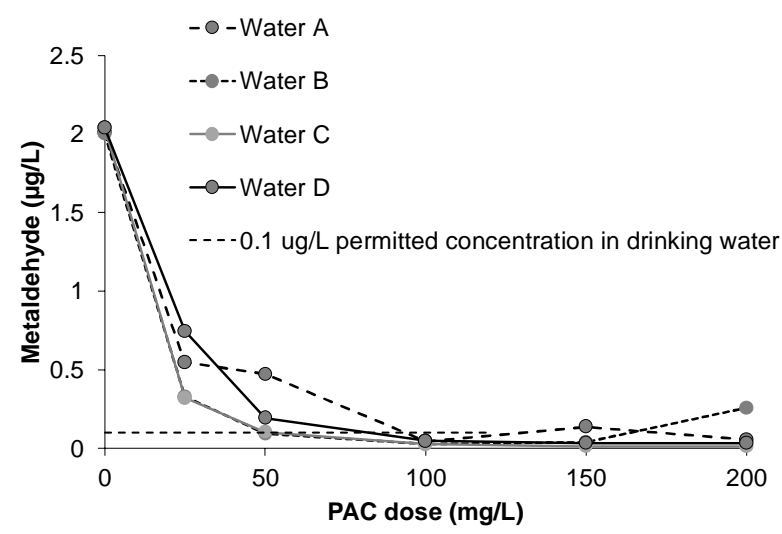

C.

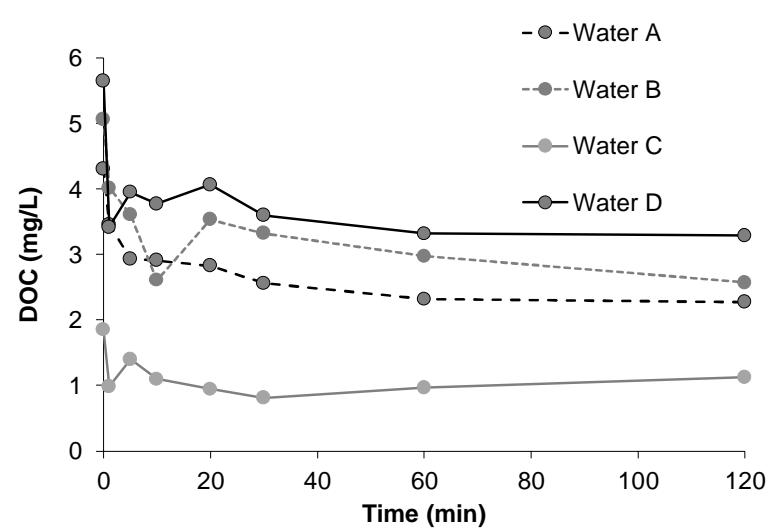

b.

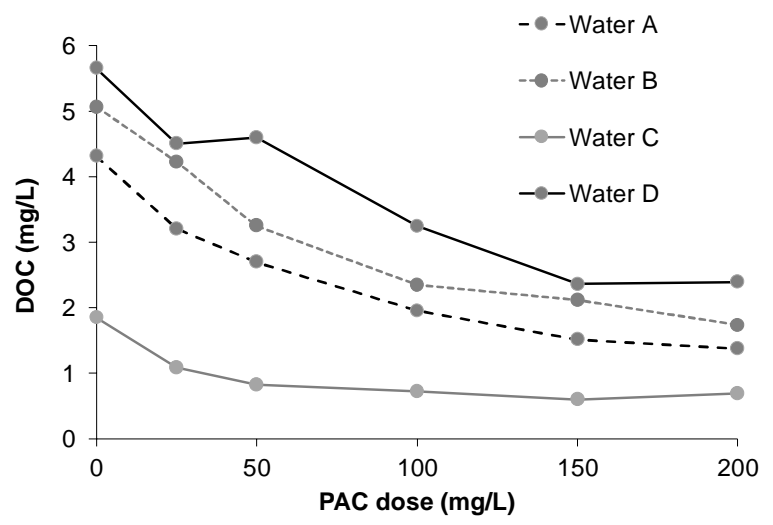

d.

Figure 1. The removal of (a) metaldehyde and (b) DOC with contact time using a dose of $50 \mathrm{mg} / \mathrm{L}$ PAC for the four different water sources. The removal of (c) pesticide and (d) DOC with increasing PAC doses for the four water sources using a contact time of 20 minutes.

The adsorption data were fitted to the pseudo-second-order rate equation using an approach used previously (Li et al., 2017):

$$
\frac{t}{Q_{t}}=\frac{1}{k Q_{e}^{2}}+\left(\frac{1}{Q_{e}}\right) t
$$

Where $t$ is the adsorption time, $Q_{t}$ is the adsorption at time $t, Q_{e}$ is the theoretical equilibrium adsorption capacity and $k$ is the pseudo-second order rate constant. A plot of $t / Q_{t}$ against $t$ enables $Q_{e}$ and $k$ to be calculated. The slope of the $t / Q_{t}$ line corresponds to $1 / Q_{e}$ from which $Q_{e}$ can be calculated, $k$ is calculated from $1 / k Q_{e}^{2}$ the intercept of the fitting line (Li et al., 2017). For each water, $k$ was 
calculated for metaldehyde $\left(k_{\text {met }}\right)$ and the DOC $\left(k_{D O C}\right)$ adsorption, as well as their theoretical equilibrium adsorption capacity $\left(Q_{e, m e t}\right.$ and $\left.Q_{e, D O C}\right)$. The data fitted the model very well (see Supporting Information, Figure S2 and S3), with $\mathrm{R}^{2}$ values $>0.99$. The obtained adsorption capacity $\left(Q_{e, m e t}\right)$ for the pesticide was consistent for the four different waters, with values between 0.039 to $0.04 \mu \mathrm{g} / \mathrm{mg}$ (Table 2). This showed that given an appropriate equilibrium time, recalcitrant pesticide could be removed to similar levels regardless of the water source and water quality. However, the rate of adsorption was much more variable, with a maximum value observed for Water $\mathrm{C}$ at $79.4 \mathrm{mg} / \mu \mathrm{g} . \mathrm{min}$ and a minimum for Water $D$ at $20.99 \mathrm{mg} / \mu \mathrm{g} . \mathrm{min}$. These results were consistent with the poor removals observed for water $D$ over contact times that would be more representative of those used at full-scale WTWs.

In the case of DOC, differences in adsorption parameters were more significant (Table 2). The adsorption capacity for DOC was several orders of magnitude greater than that seen for metaldehyde, with $Q_{e, D O C}$ values between 14.8 and $50.5 \mathrm{mg} / \mathrm{g}$. This was a reflection of the higher initial starting concentration of DOC and a higher affinity for adsorption (Li et al., 2017). However, the adsorption rate $k_{D O C}$ was slower when compared to the values seen for metaldehyde, with values between 0.003 and $0.029 \mathrm{mg} / \mu \mathrm{g} . \mathrm{min}$. This was due to the more heterogeneous nature of the organic matter present in the source waters, resulting in slower migration of a mixture of organic compounds into the pores of the activated carbon. Features of the DOC including its variable size, hydrophobicity and charge will all influence the speed at which adsorption occurs (Golea et al., 2020). 
The relationship between bulk water quality and adsorption capacity and rate identified that $k_{\text {met }}$ was inversely linked to the initial DOC such that the pesticide was removed faster when there was less competing background organic matter present (Figure 2). On other hand, $Q_{e, \text { met }}$ was stable independently of the initial DOC, showing that given enough time similar pesticide equilibrium concentrations can be achieved even though the adsorption process was slower, a result consistent with previous studies (Li et al., 2019). This is because small molecules such as metaldehyde can ultimately access micropores and mesopores over time, while bulk organic matter is more limited to the surface of the PAC or its macropores. The $Q_{e, D O C}$ was increased as the DOC concentration in the source water increased. The lowest affinity for adsorption was seen for the organic matter present in water C which had a $Q_{e D O C}$ of $14.8 \mu \mathrm{g} / \mathrm{mg}$ (initial DOC $2.6 \mathrm{mg} / \mathrm{L}$ ). This compared to values of $Q_{e D O C}$ of $50.5 \mu \mathrm{g} / \mathrm{mg}$ for water B (initial DOC 5.8) and $48.5 \mu \mathrm{g} / \mathrm{mg}$ for water D (initial DOC $6.5 \mathrm{mg} / \mathrm{L}$ ). The concentration gradient and the nature of the organic compounds present in each of the water sources were therefore shown to control overall removal of DOC.

Table 2. Adsorption capacity and adsorption rate constant for metaldehyde and DOC for the four water sources.

\begin{tabular}{|l|c|c|c|c|}
\hline & \multicolumn{2}{|c|}{ Metaldehyde } & \multicolumn{2}{c|}{ DOC } \\
\hline & $\begin{array}{c}Q_{e, \text { met }} \\
(\mu \mathrm{g} / \mathrm{mg})\end{array}$ & $\begin{array}{c}k_{\text {met }} \\
(\mathrm{mg} / \mu \mathrm{gg} \cdot \mathrm{min})\end{array}$ & $\begin{array}{c}Q_{e, \mathrm{DOC}} \\
(\mu \mathrm{g} / \mathrm{mg})\end{array}$ & $\begin{array}{c}k_{D O C} \\
(\mathrm{mg} / \mu \mathrm{m} \cdot \mathrm{min})\end{array}$ \\
\hline Water $\mathrm{A}$ & 0.04 & 34.3 & 42.0 & 0.005 \\
\hline Water B & 0.04 & 39.0 & 50.5 & 0.003 \\
\hline Water C & 0.04 & 79.5 & 14.8 & 0.029 \\
\hline Water D & 0.04 & 21.0 & 48.5 & 0.005 \\
\hline
\end{tabular}




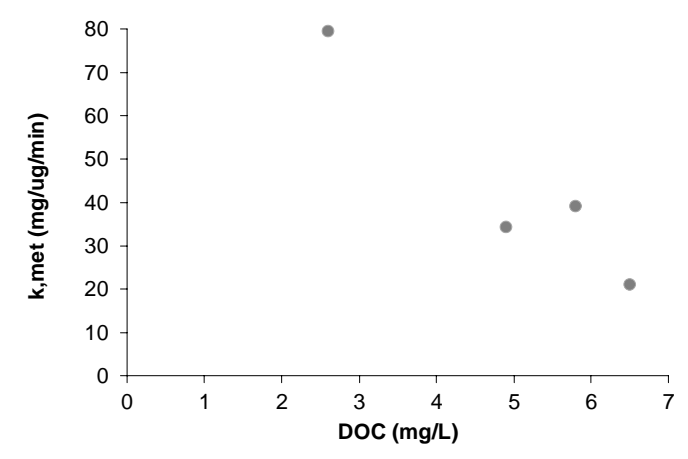

a. Pesticide adsorption rate

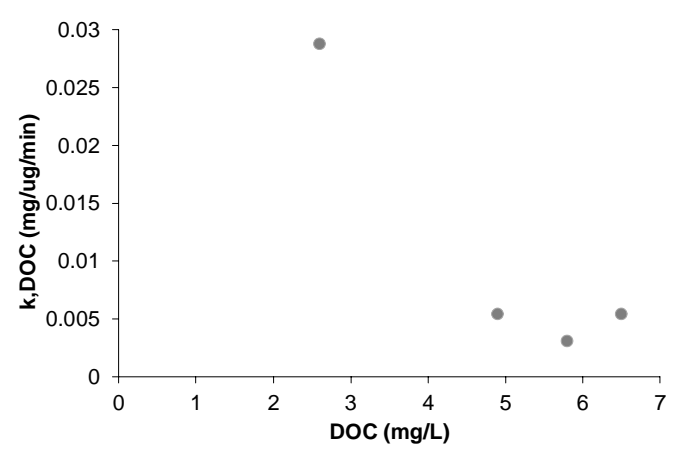

C. DOC adsorption rate

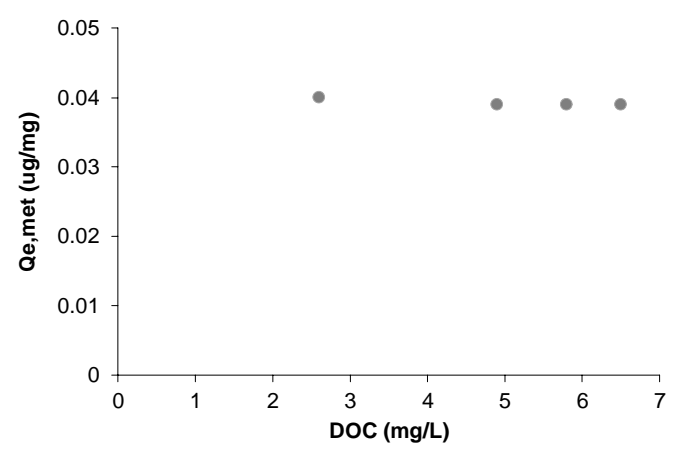

b. Pesticide adsorption capacity

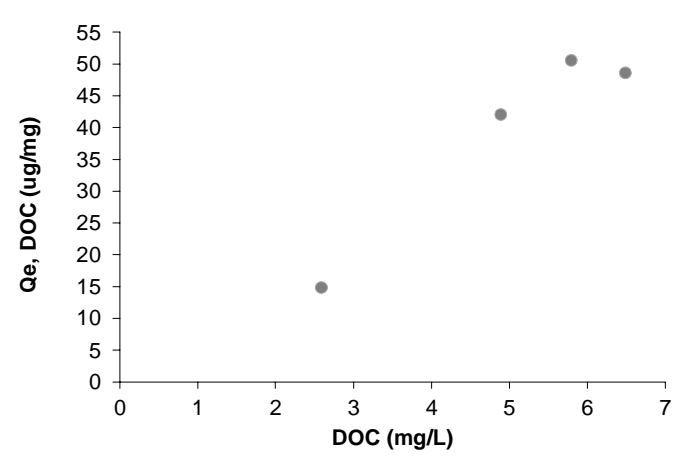

d. DOC adsorption capacity

Figure 2. The relationship between initial water quality and the rate and capacity of adsorption for metaldehyde ( $a$ and $b$ ) and DOC (c and d).

\subsection{Coagulation and clarification of water sources}

The following results consider the integration of adsorption with the coagulation and clarification processes. In these experiments, water D was selected due to it posing the most significant challenge with respect to competing background organic matter being present, having the highest initial DOC of the water sources investigated at $6.54 \mathrm{mg} / \mathrm{L}\left(\mathrm{UV}_{254}\right.$ was $\left.13.61 / \mathrm{m}\right)$. The coagulation of water $\mathrm{D}$ was carried out with and without PAC dosing. Preliminary tests established that the optimum coagulant dose for the water was $7 \mathrm{mg} / \mathrm{L}$ as $\mathrm{Fe}$ at $\mathrm{pH} 4.5$. These coagulation conditions were then applied to water dosed with increasing PAC concentrations to see the impact on clarification and pesticide removal (SI Figure 
4). Clarification after flotation was assessed based on residual $U V_{254}$ and turbidity. The $\mathrm{UV}_{254}$ decreased from 11.0 to $1.01 / \mathrm{m}$ as the PAC dose increased from 0 to $200 \mathrm{mg} / \mathrm{L}$. On the contrary, residual turbidity was higher as the PAC dose was increased from to 0 to $200 \mathrm{mg} / \mathrm{L}$ ( 0.8 to $2.8 \mathrm{NTU}$ ). For the PAC dose that enabled pesticide compliance $(100 \mathrm{mg} / \mathrm{L})$, the turbidity increased by $1.6 \mathrm{NTU}$ compared to the control where no PAC was added to the water. These results show that the addition of PAC into the clarification process causes a small deterioration in water quality, due to the presence of PAC particles not captured in flocs.

The PAC dosing position was therefore investigated to determine whether removals could be improved (Figure 3). With respect to metaldehyde, the highest removal was achieved when only PAC was dosed, resulting in a residual concentration of $0.09 \mu \mathrm{g} / \mathrm{L}$ residual concentration. The adsorbent alone reduced the $\mathrm{DOC}$ and $\mathrm{UV}_{254}$ by $2.7 \mathrm{mg} / \mathrm{L}$ and $8.8 \mathrm{abs} / \mathrm{m}$. With no coagulant, the residual turbidity was high after the clarification phase with a turbidity of 28.7 NTU and suspended solids of $55 \mathrm{mg} / \mathrm{L}$. When adsorbent dosing was combined with coagulation, there were some reductions in the removal of the pesticide showing some interference in removal of micropollutants when PAC was coagulated into the floc (Figure 3a). When PAC was dosed prior to the coagulant, residual metaldehyde was $0.18 \mu \mathrm{g} / \mathrm{L}$, with no difference observed for the 1 or 5 minute contact time. Very similar residual metaldehyde was observed when PAC was added after the coagulant at $0.16 \mu \mathrm{g} / \mathrm{L}$. The lowest pesticide removal was seen when PAC and coagulant were dosed simultaneously, resulting in residual metaldehyde of $0.3 \mu \mathrm{g} / \mathrm{L}$. When dosed together part of the pesticide removal capacity was lost. A plausible mechanism explaining this observation is that when 
dosed simultaneously, PAC and coagulant immediately interact, with the coagulant occupying adsorption sites on the adsorbent that would otherwise would be available. This is a result consistent with investigations on taste and odour removal by PAC, where performance declined as the coagulant dose increased (Ho et al., 2005). Kouras et al. (1998) similarly reported that the removal of lindane by PAC decreased by up to $20 \%$ when coagulant was added. Dosing PAC either side of the precipitation of the coagulant reduced this interaction.

However, when PAC particles were trapped in a floc, the adsorption achievable in the reaction time was reduced regardless of dosing sequence when compared with the PAC system in the absence of coagulant. This was thought to be a result of both a reduction in accessible adsorption sites and a slowing of adsorption kinetics. When PAC was dosed alone, all of the adsorption sites were available for the pesticide adsorption and it was able to more easily access the pores. On the contrary, when the coagulant was present, some of the adsorption sites of the PAC may have been blocked by coagulant precipitates, reducing the PAC adsorption capacity. In addition, when PAC is trapped in a floc the pesticide diffusion pathway is also significantly increased, resulting in slower rates of adsorption (Ho et al., 2005).

Compared to dosing the adsorbent alone, DOC removal and residual turbidity were much higher when combined coagulation and PAC was applied. For DOC, the residual achieved after 1 and 5 minutes of PAC contact before the coagulant was 1.30 and $1.17 \mathrm{mg} / \mathrm{L}$, respectively (Figure $3 \mathrm{~b}$ ). When coagulant was dosed, 
there was a small improvement in DOC removal with residual levels of 0.87 and $0.75 \mathrm{mg} / \mathrm{L}$ for the 1 and 5 minute coagulant contact time, respectively. Simultaneous dosing resulted in residual DOC of $1.30 \mathrm{mg} / \mathrm{L}$.

With respect to particle removal, improvements were seen when PAC was dosed prior to the coagulant, with residual turbidity values of $0.9 \mathrm{NTU}$ and $2 \mathrm{mg} / \mathrm{L}$ for suspended solids for PAC-Coag. This compared to values of $1.2 \mathrm{NTU}$ and $7 \mathrm{mg} / \mathrm{L}$ for Coag-PAC and 3.5 NTU and $3 \mathrm{mg} / \mathrm{L}$ suspended solids. Dosing PAC into clarification systems necessitates a compromise between the rate of adsorption, the amount of PAC required for effective micropollutant removal and the ability to effectively remove the PAC from the water in downstream clarification and filtration processes. As has been shown, doses of PAC of around $100 \mathrm{mg} / \mathrm{L}$ would be required to effectively remove the recalcitrant pesticide metaldehyde. The results show that this would cause a small increase in the turbidity of water after clarification that would place some additional loading onto downstream filtration processes. 


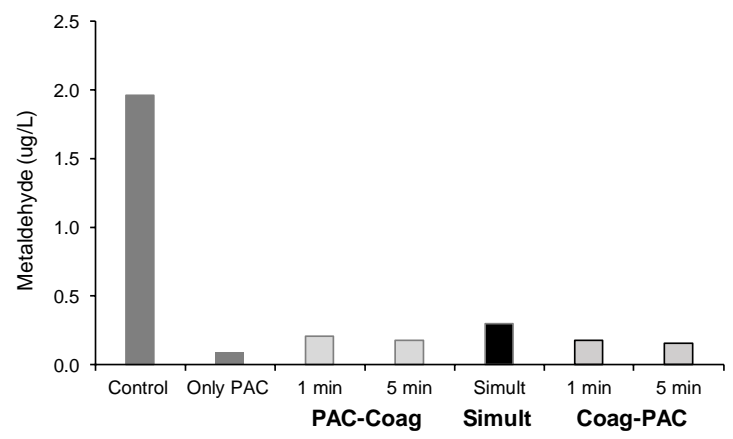

a. Metaldehyde

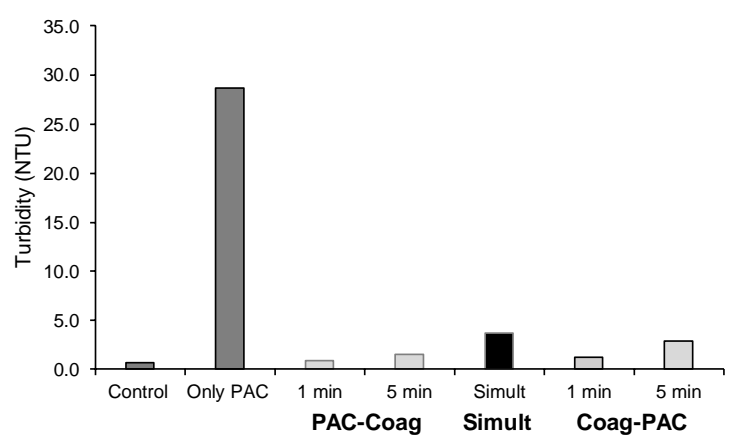

c. Turbidity

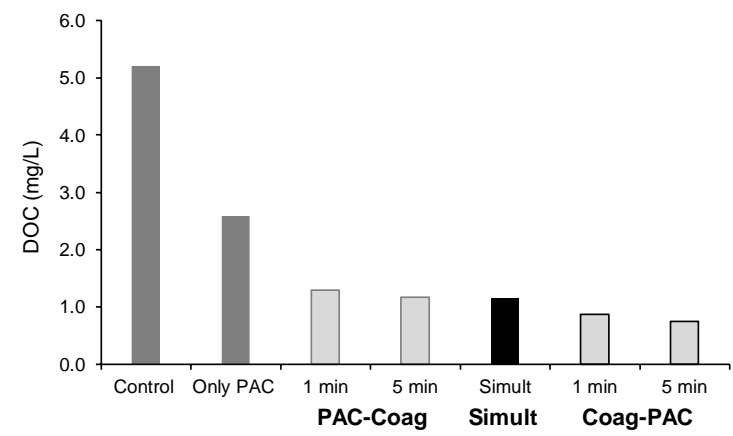

b. DOC

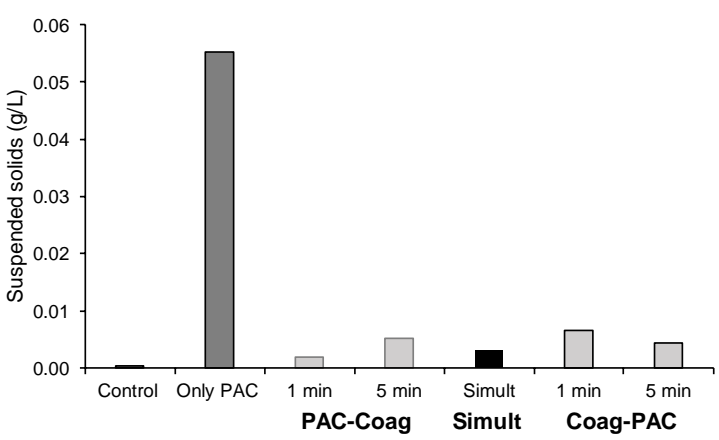

d. Suspended Solids

Figure 3. Results of (a) DOC, (b) metaldehyde, (c) turbidity, and (d) suspended solids from the study of dosing position of PAC. In these experiments $100 \mathrm{mg} / \mathrm{L}$ of PAC and $7 \mathrm{mg} / \mathrm{L}$ as Fe of coagulant was dosed.

\subsection{Floc properties with and without PAC}

To determine the impact of dosing PAC on floc formation and clarification, floc growth and sizing experiments were undertaken. Initial tests were undertaken to show how the dosing position of PAC influenced the growth and size of flocs (Figure 4). All the flocs approached a steady-state floc size after 5 minutes of flocculation for all of the dosing sequences. The PAC-Coag and Simult systems reached a similar floc size in the range of $700-900 \mu \mathrm{m}$, the Coag-PAC floc size were significantly smaller at $300-500 \mu \mathrm{m}$. This occurred because during the dosing and dispersal of the PAC after the coagulant had been added, flocs were broken soon after they had formed. The regrowth capacity of flocs was low once 
they have undergone breakage. This is a phenomenon observed for many flocculated systems including coagulation of algae, natural organic matter, mineral turbidity and wastewater as floc components reorganise into stable smaller structures once broken (Jarvis et al., 2005b; Jarvis et al., 2008; Yu et al., 2016). The exception to this is when polymer is dosed, as there are opportunities for polymer molecules to reform bonds once broken (Fabrizi et al., 2012). There was also an increase in the proportion of small particles between 27 and $98 \mu \mathrm{m}$ for the Coag-PAC dosing when compared to the other systems (inset in Figure 4). These sizes were consistent with PAC particles that had not been incorporated into the floc. The increased proportion of small particles also helped explain why the residual turbidity was higher for the Coag-PAC dosing system following flotation as these smaller particles would take longer to clarify from the water.

Further investigations were undertaken for flocs formed from PAC-Coag dosing due to the similar levels of pesticide removal observed alongside improved clarification when compared to other dosing strategies. It was evident from visual inspection that PAC particles were effectively incorporated into the bulk floc structure and that with increasing dose, the density of PAC particles captured in the floc increased (SI, Figure S5). There were also differences in the size of flocs formed with and without PAC dosing (Figure 5). During the first minutes of slow mixing, the PAC aggregated into larger flocs that reached median sizes of between 338-538 $\mu \mathrm{m}$ after 4 minutes, ultimately reaching floc sizes $>800 \mu \mathrm{m}$ after 15 minutes of flocculation. These flocs sizes were significantly larger than those observed for a control test, where no PAC had been added to the water which 
reached $666 \mu \mathrm{m}$. These results were consistent with those seen previously for the coagulation of humic acid with and without PAC (Huang et al., 2020). The presence of PAC particles in water helps to encourage rapid and large growth of flocs by increasing particle collisions and acting as seeding points around which flocs can grow rapidly. This is a mechanism exploited in many flocculation systems to encourage additional removal of contaminants, such as metal removal from industrial wastewater (Chen et al., 2016) and natural organic matter removal from drinking water (Lapointe and Barbeau, 2018).

On exposure to increased shear rate, the median floc size decreased rapidly to plateau at sizes between $275-430 \mu \mathrm{m}$ after 2 minutes. Once the shear rate was reduced again, some limited floc growth was observed. Flocs grew to between $67-116 \mu \mathrm{m}$ during the two first minutes after returning to the normal flocculation conditions (30 rpm). Re-growth was limited, consistent with that seen previously. Strength (SF) and regrowth factors (RF) were calculated for the different PAC doses (Table 3). The higher the value of the strength factor, the stronger the floc is considered, and the less sensitive it is to break under shear conditions (Jarvis et al., 2005a). Similarly, high values for the regrowth factor indicate a better capacity of flocs to reform, so high values of strength and regrowth factor are desirable. The strength factors varied from 18.0 (50 mg/L of PAC) to 48.3 (only coagulant) and the regrowth factors from 49.7 (50 mg/L of PAC) to $73.6(0 \mathrm{mg} / \mathrm{L}$ of PAC). Flocs therefore had higher initial strength and better proportional recovery when only the coagulant was present reaching $68 \%$ of their initial size during regrowth $(454 \mu \mathrm{m})$. In part, this was a reflection of the smaller initial size of the flocs formed when only PAC was dosed and the similar absolute size of 
flocs formed following re-growth. However, the more compact floc structure and relative resistance to degradation may also indicate increased bonding strength between microflocs of coagulated precipitates compared to those formed between PAC particles and the precipitates. In the case of PAC dosing, a dose of $25 \mathrm{mg} / \mathrm{L}$ formed flocs that broke less (higher breakage factors) and regrew better (Growth: $865 \mu \mathrm{m}$, Regrowth: $607 \mu \mathrm{m}$ ) than any other PAC doses. Floc strength and breakage factors were similar for higher PAC doses, reflecting the similar growth and breakage profiles observed for these systems (Figure 5). Further analysis of the floc size distributions at key points in the growth, breakage and re-growth of the flocs showed that there were differences in the range of floc sizes observed (Figure 6). For example, considering a PAC dose of $100 \mathrm{mg} / \mathrm{L}$ that represented conditions under which effective metaldehyde removal might be achieved, floc sizes between 52 and $3500 \mu \mathrm{m}$ were observed during the growth phase. Following the breakage phase the distribution shifted to smaller floc sizes between 27 and $859 \mu \mathrm{m}$ and there was an increase in the particles between 27$58 \mu \mathrm{m}$ (inset Figure $5 \mathrm{~d}$ ). This secondary distribution was evident for all of the PAC dose systems, but a similar shoulder in the distribution was absent for the control test (coagulant only). These small particles were consistent with PAC particles that were released from flocs. The same secondary distribution was evident following the regrowth phase for the PAC dosed systems showing that these PAC particles could not be recaptured during regrowth. 


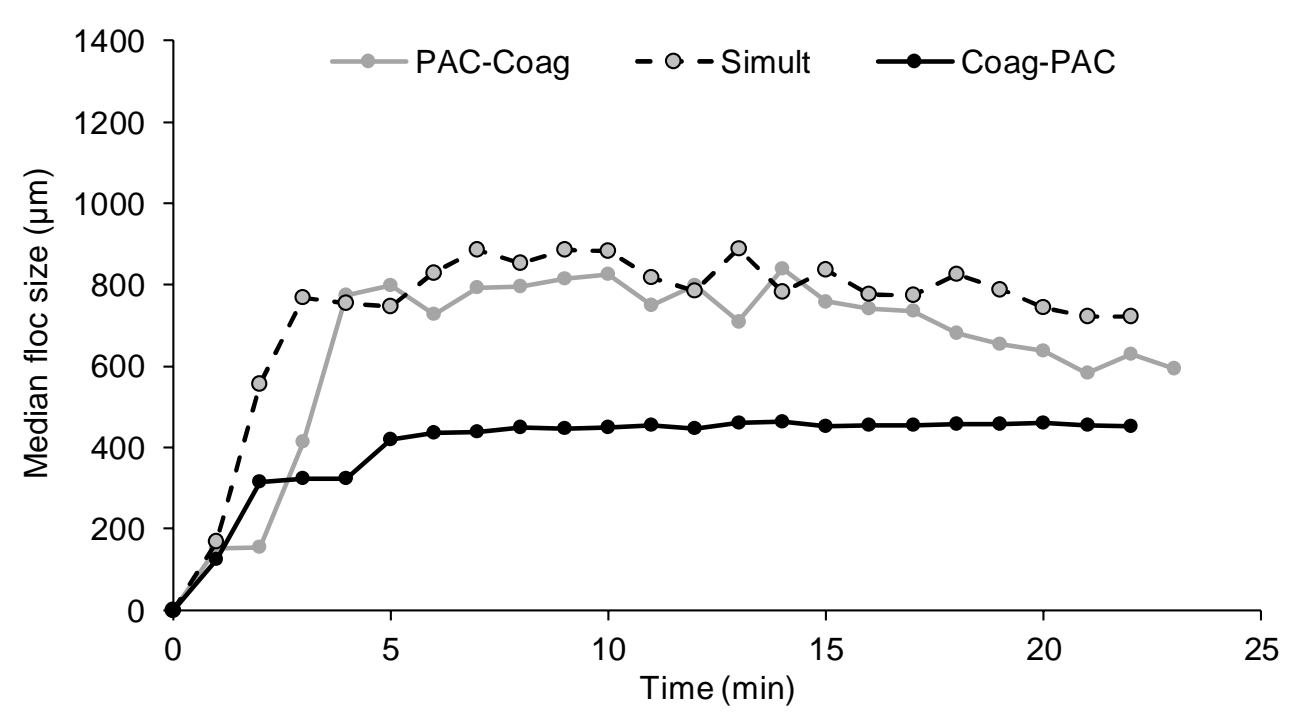

a.

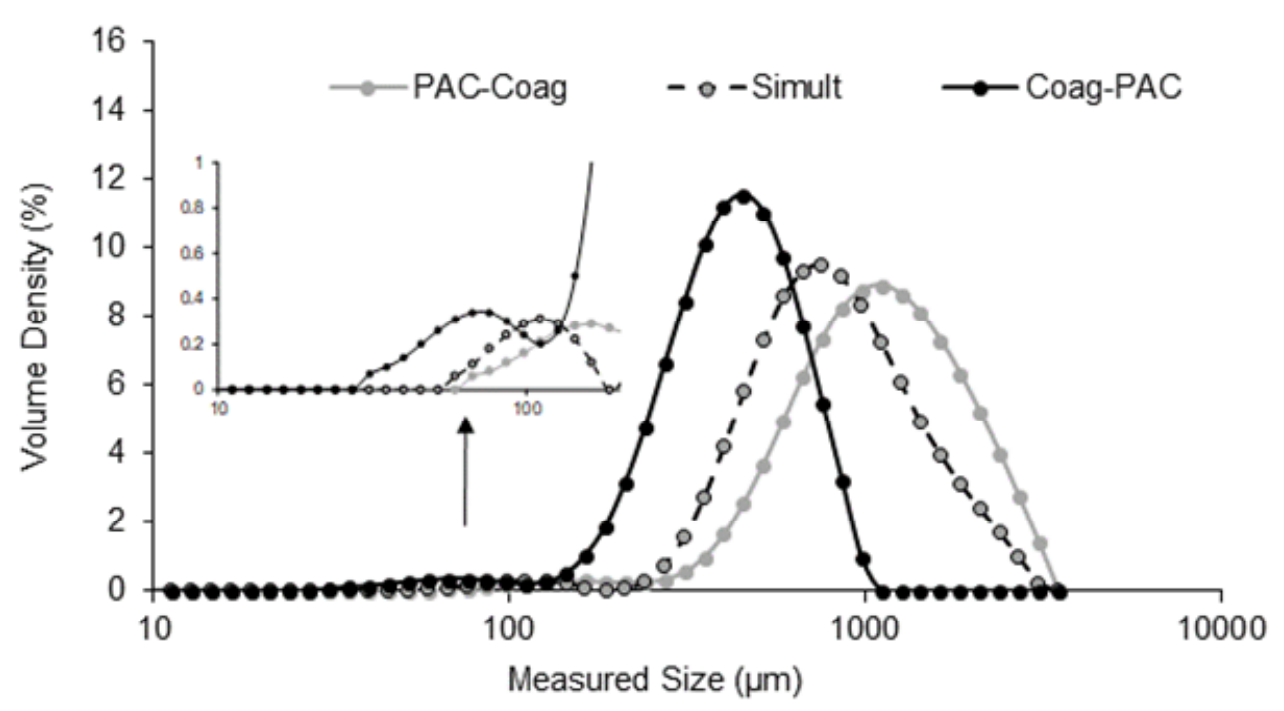

b.

Figure 4. Influence of dosing position on floc growth and size. a) median floc size with flocculation time. b) particle size distribution after 15 minutes flocculation time 


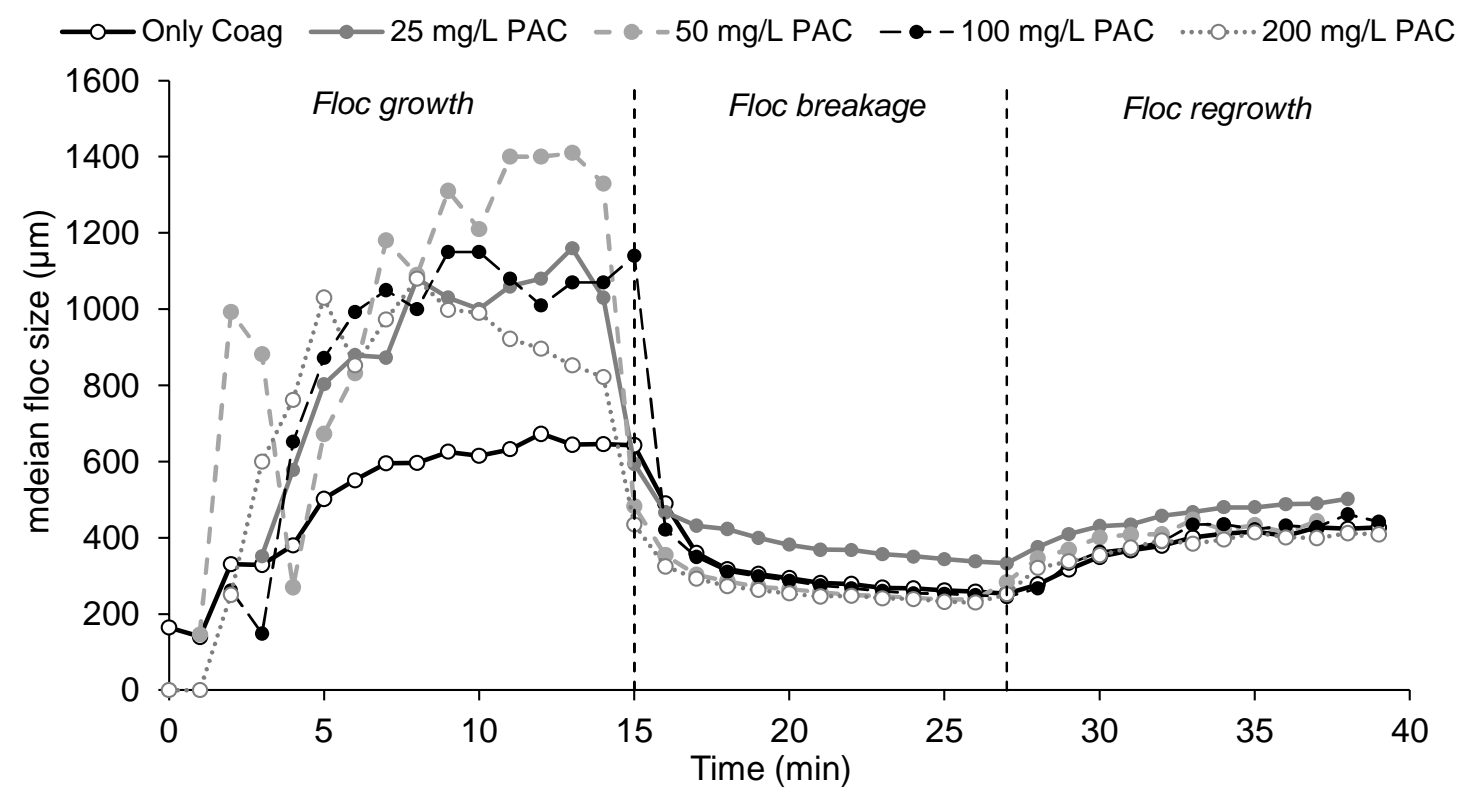

Figure 5. Results of floc growth, breakage, and regrowth with increasing PAC dose. 


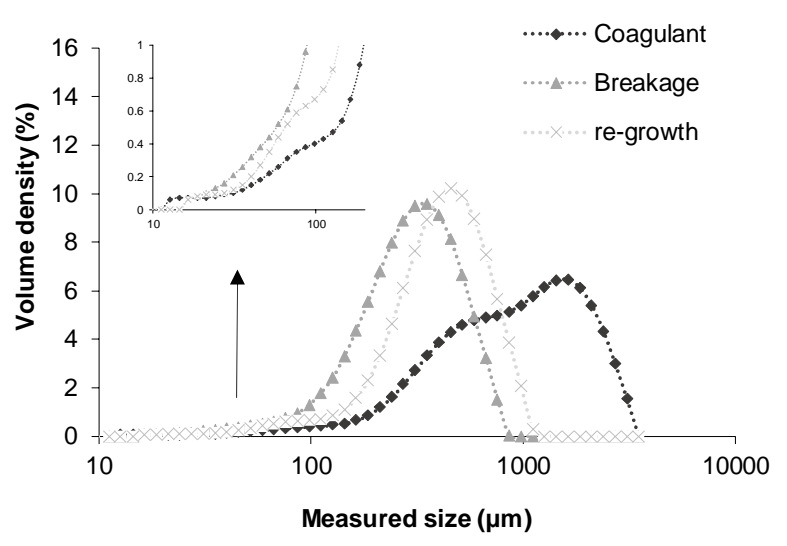

a. Only coagulant

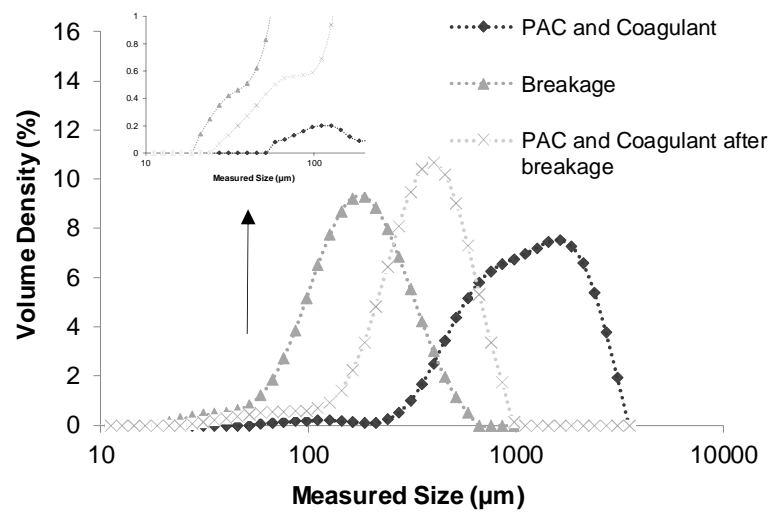

C. $50 \mathrm{mg} / \mathrm{L}$ PAC

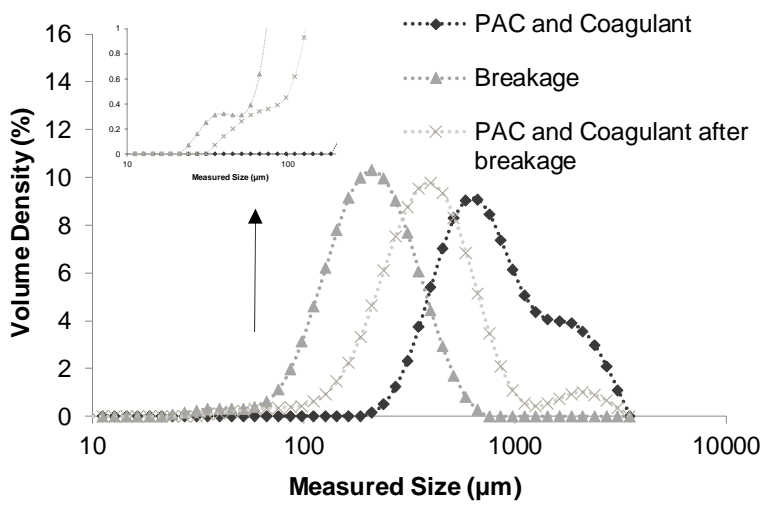

e. $200 \mathrm{mg} / \mathrm{L}$ PAC

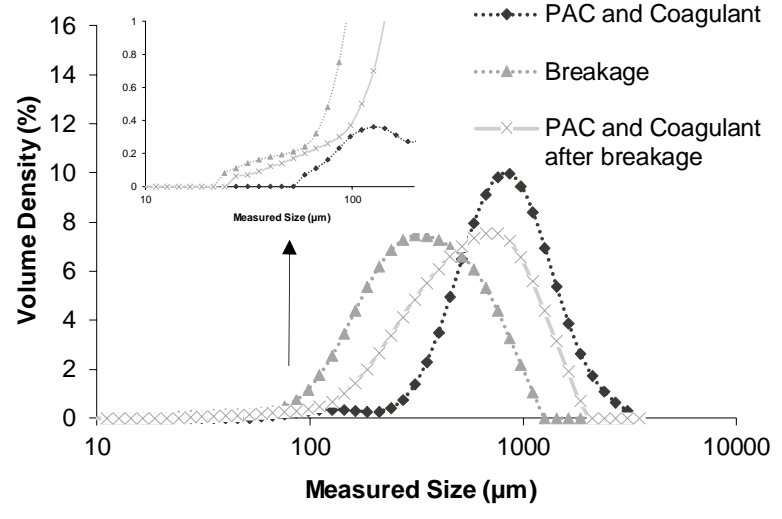

b. $25 \mathrm{mg} / \mathrm{L}$ PAC

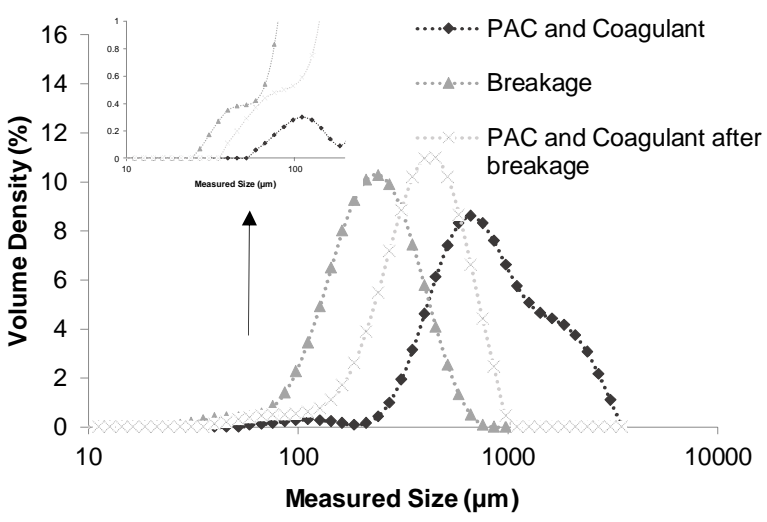

d. $100 \mathrm{mg} / \mathrm{L}$ PAC

Figure 6. Particle size distribution of flocs during growth, breakage, and regrowth for systems with and without PAC. The inset figure shows detail of the small flocs present in the system. 
Table 3. Floc strength and re-growth factors for flocs with increasing PAC concentration.

\begin{tabular}{|c|c|c|}
\hline $\begin{array}{c}\text { PAC concentration } \\
(\mathrm{mg} / \mathrm{L})\end{array}$ & Strength Factor & Regrowth Factor \\
\hline 0 & 48 & 74 \\
\hline 25 & 43 & 61 \\
\hline 50 & 18 & 50 \\
\hline 100 & 30 & 57 \\
\hline 200 & 30 & 58 \\
\hline
\end{tabular}

\subsection{Implications for application at full-scale WTWs}

Dosing PAC into clarification systems necessitates a compromise between the kinetics and the amount of PAC required for effective micropollutant removal and the abilities to effectively remove the PAC from the water in the downstream WTW. The results showed that there was no difference in pesticide removal between dosing PAC or coagulant first, a reflection that the dose and contact time was effective for combined adsorption pesticide and DOC, overcoming any kinetic limitations for this water source. If lower PAC doses were necessary, dosing the coagulant first might be an advantage, since part of the NOM would be removed by the time that PAC was dosed. Such an approach was shown to be most effective for removal of pesticides from other water sources (Li et al., 2020, Tomaszewska et al., 2004). However, the poorer quality of clarified water with increased suspended solids would limit the application of PAC after coagulant for most typical water treatment flowsheets.

PAC doses around $100 \mathrm{mg} / \mathrm{L}$ would be required to effectively remove the recalcitrant pesticide metaldehyde when dosed into raw water prior to coagulation. Previous research has suggested that doses of 50 and $100 \mathrm{mg} / \mathrm{L}$ PAC may be challenging for application in many WTWs as a result of solids 
carryover onto filters reducing filter run times (Ho et al., 2011). However, operational doses of PAC up to and including $100 \mathrm{mg} / \mathrm{L}$ have been reported elsewhere (US Environmental Protection Agency, 2017). The current results show that the application of this PAC concentration would result in a slight increase in water suspended solids and turbidity after clarification relative to a control without PAC. The performance of downstream filtration systems was beyond the scope of this research, but the results imply that modifications to filter operation may be required when PAC is dosed at such high concentrations. This might include reduced filter times and enhanced backwashing protocols.

Other modifications may also be considered. For example, adaptations to the DAF process may enable better removal of residual PAC. Although the size of PAC particles is within the recommended range suitable for flotation according to previous studies (10-30 $\mu \mathrm{m}$ ) (Edzwald et al., 1992), a suspension of PAC particles without coagulant were poorly removed by flotation. PAC typically has a point of zero charge (PZC) between $\mathrm{pH} 6$ and 8 , being positively charged at $\mathrm{pH}$ below this and negatively charged at higher pH (Adam, 2016). However, once present in organic laden water, the PAC will assume the characteristics of the background organic matter as it adsorbs onto the sorbent surface, shifting the PZC to lower $\mathrm{pH}$ and becoming negatively charged under the prevailing conditions used in these experiments. As the electrostatic interactions between the bubble and the particle control the adhesion, there will be repulsion between the negatively charged PAC particles and air bubbles formed by DAF $(-25 \mathrm{mV})$, leading to repulsion (Henderson et al, 2008; Rao et al., 2018). Although the addition of positively charged coagulant reduces the net negative charge on the PAC 
particles, the use of bubble surface modifiers such as those used in the PosiDAF process, could be used as an alternative to pre-treatment in determined situations, or to increase the removal rate. In PosiDAF, bubble surface modification can be achieved by adding a chemical surfactant or polymer to the saturator of a DAF unit (Henderson et al., 2008; Henderson et al., 2010). Similarly, polymer could be used as a flocculation aid to help increase the capture of PAC particles during the coagulation/flocculation process (Lapointe and Barbeau, 2020).

Invariably, if we are expecting clarification processes to carry put multiple functions (bulk removal and micropollutant removal), then some compromises must be expected. PAC dosing has been shown to be a realistic option for removal of a persistent micropollutant that is likely to have only a small impact on operational practice, much lower than would be expected for implementation of high energy processes such as AOPs.

\section{Conclusions}

The PAC dose required to remove the metaldehyde to under $0.1 \mu \mathrm{g} / \mathrm{L}$ for all of the four water sources was determined to be $100 \mathrm{mg} / \mathrm{L}$ with a contact time of 20 minutes. The pseudo-second-order model provided the best fit for modelling the kinetics of metaldehyde adsorption by PAC. The removal of pesticide was faster when there was less background DOC present in the source water, although the modelled equilibrium capacity for pesticide onto the PAC was similar, irrespective of the DOC. PAC was able to adsorb pesticide when it was incorporated into a floc, but the amount of the pollutant removed during the jar test contact period 
was reduced compared to when PAC was present in the absence of coagulant. Simultaneous addition of PAC and coagulant resulted in lower removal rates of pesticide compared to when they were dosed separately. Coagulant dosed before the PAC achieved better NOM removal compared to dosing PAC first or following simultaneous addition. After the application of the $100 \mathrm{mg} / \mathrm{L} \mathrm{PAC}$, treated water suspended solids were higher than for a non-PAC dosed system. For the water source investigated in detail (Water D), PAC dosing prior to coagulant was recommended. Further research is required to understand the impact of source water turbidity on PAC dosing position such that more universal application of the results can be achieved. In addition, work is needed to investigate the impact of increased solids loading in clarified water from residual PAC particles on downstream filtration processes.

\section{Acknowledgement}

The authors gratefully thank Doosan Enpure for funding this research and allowing use of their testing facilities. 


\section{References}

Adam, O. E. A. (2016) Removal of resorcinol from aqueous solution by activated carbon: Isotherms, thermodynamics and kinetics. American Chemical Science Journal, 16 (1), 1-13. doi.org/10.9734/ACSJ/2016/27637.

APHA (1992) Standard Methods for the examination of water and waste water, American Public Health Association.

Autin, O., Hart, J., Jarvis, P., MacAdam, J., Parsons, S. A. and Jefferson, B. (2012). Comparison of $\mathrm{UV} / \mathrm{H}_{2} \mathrm{O}_{2}$ and $\mathrm{UV} / \mathrm{TiO} 2$ for the degradation of metaldehyde: Kinetics and the impact of background organics. Water Research, 46(17), 56555662. doi.org/10.1016/j.watres.2012.07.057.

Bernal-Romero del Hombre Bueno, M., Boluda-Botella, N. and Prats Rico, D. (2019). Removal of emerging pollutants in water treatment plants: adsorption of methyl and propylparaben onto powdered activated carbon. Adsorption, 25, 983. doi.org/10.1007/s10450-019-00120-7.

Bizi, M (2019) Activated carbon and the principal mineral constituents of a natural soil in the presence of carbamazepine. Water, 11, 2290. doi.org/10.3390/w11112290.

Castle, G.D., Mills, G.A., Gravell, A., Jones, L., Townsend, I., Cameron, D.G. and Fones, G.R. (2017). Review of the molluscicide metaldehyde in the environment. Environmental Science: Water Research and Technology, 3(3), pp. 415-428. doi.org/10.1039/c7ew00039a

Chen, Y, Luo, M. and Cai, W. (2016) Influence of operating parameters on the performance of magnetic seeding flocculation. Environmental Science and Pollution Research, 23, 2873-288. doi.org/10.1007/s11356-015-5601-5. 
Cook, D., Newcombe, G. and Sztajnbok, P. (2001). The application of powdered activated carbon for MIB and geosmin removal: Predicting PAC doses in four raw waters. Water Research, 35 (5), 1325-1333. doi.org/10.1016/S00431354(00)00363-8.

Cosgrove, S., Jefferson, B., Jarvis, P. (2019). Pesticide removal from drinking water sources by adsorption: a review. Environmental Technology Reviews, 8(1), 1-24. doi.org/10.1080/21622515.2019.1593514.

Crossley, I. A. and Valade, M. T. (2006). A review of the technological developments of dissolved air flotation. Journal of Water Supply: Research and Technology—AQUA, 55(7-8), 479-491. doi.org/10.2166/aqua.2006.057.

Duan, J., Wilson, F., Graham, N. and Tay, J. (2003). Adsorption of humic acid by powdered activated carbon in saline water conditions. Desalination, 151, 53-66. doi.org/10.1016/S0011-9164(02)00972-4.

Edzwald, J. K. (2010). Dissolved air flotation and me. Water Research, 44 (7), 2077-2106. doi.org/10.1016/j.watres.2009.12.040.

Edzwald, J. K., Walsh, J. P., Kaminski, G. S., Dunn, H. J., Journal, S., Water, A., Association, W., March, R. U., Edzwald, J. K., Walsh, J. P., Kaminski, G. S. and Dunn, H. J. (1992). Flocculation and Air requirements for dissolved air flotation. American Water Works Association, 84 (3), 92-100. doi.org/10.1002/j.15518833.1992.tb07325.x

Etchepare, R., Oliveira, H., Azevedo, A. and Rubio, J. (2017). Separation of emulsified crude oil in saline water by dissolved air flotation with micro and nanobubbles. Separation and Purification Technology, 186, 326-332. doi.org/10.1016/j.seppur.2017.06.007. 
Golea, D., Jarvis, P., Jefferson, B., Sutherland, S., Moore, G., Parsons, S. A., Judd, S. (2020). Influence of GAC media properties on NOM DBP formation potential removal from drinking water. Water Research, 174, 115613. doi.org/10.1016/j.watres.2020.115613

Han, M. Y. (2002). Modeling of DAF: The effect of particle and bubble characteristics. Journal of Water Supply: Research and Technology - AQUA, 51(1), pp. 27-34. doi.org/10.2166/aqua.2002.0003

Henderson, R. K., Parsons, S. A. and Jefferson, B. (2008). Surfactants as bubble surface modifiers in the flotation of algae: dissolved air flotation that utilizes a chemically modified bubble surface, 42 (13), 4883-4888. doi.org/10.1021/es702649h.

Henderson, R. K., Parsons, S. A., Jefferson, B., Henderson, R. K., Parsons, S. A. and Jefferson, B. (2010). Polymers as bubble surface modifiers in the flotation of algae, Environmental Technology, $31 \quad$ (7), 781-290. doi.org/10.1080/09593331003663302.

Huang, X., Wan, Y., Shi, B., Shi, J. (2020) Effects of powdered activated carbon on the coagulation-flocculation process in humic acid and humic acid-kaolin water treatment.

Chemosphere, 238 , 124637. doi.org/10.1016/j.chemosphere.2019.124637 Ho, L. and Newcombe, G. (2005). Effect of NOM, turbidity and floc size on the PAC adsorption of MIB during alum coagulation. Water Research, 39 (15), 36683674. doi.org/10.1016/j.watres.2005.06.028.

Ho, L., Lambling, P., Bustamante, H., Duker, P. and Newcombe, G. (2011) Application of powdered activated carbon for the adsorption of 
cylindrospermopsin and microcystin toxins from drinking water supplies. Water Research, 45 (9), 2954-2964. doi.org/10.1016/j.watres.2011.03.014.

Jarvis, P., Jefferson, B., Parsons, S.A. (2005a). Breakage, regrowth, and fractal nature of natural organic matter flocs. Environmental Science and Technology 39(7), 2307-2314. doi.org/10.1021/es048854x.

Jarvis, P., Jefferson, B., Gregory, J. and Parsons, S. A. (2005b). A review of floc strength and breakage. Water Research, 39(14), 3121-3137. doi.org/10.1016/j.watres.2005.05.022.

Jarvis, P., Buckingham, P., Holden, B., Jefferson, B (2009). Low energy ballasted flotation. Water Research, $43 \quad$ (14), 3427-3434. doi.org/10.1016/j.watres.2009.05.003.

Kay, P. and Grayson, R. (2014). Using water industry data to assess the metaldehyde pollution problem. Water and Environment Journal, 28(3), 410-417. doi.org/10.1111/wej.12056.

Kouras, A., Zouboulis, A., Samara, C. and Kouimtzis, T. (1995). Removal of pesticides from surface waters by combined physicochemical processes. Part I: Dodine', Chemosphere, 30(12), 2307-2315. doi.org/10.1016/00456535(95)00103-F.

Kouras, A., Zouboulis, A., Samara, C. and Kouimtzis, T. (1998). Removal of pesticides from aqueous solutions by combined physicochemical processes The behaviour of lindane. Environmental Pollution, 103(2-3), 193-202. doi.org/10.1016/S0269-7491(98)00124-9.

Lapointe, M. and Barbeau, B. (2018). Selection of media for the design of ballasted flocculation processes. Water Research, 147, 25-32. doi.org/10.1016/j.watres.2018.09.041. 
Lapointe, M. and Barbeau, B. (2020). Understanding the roles and characterizing the intrinsic properties of synthetic vs. natural polymers to improve clarification through interparticle Bridging: A review. Separation and Purification Technology, 231 (16), 115893. doi.org/10.1016/j.seppur.2019.115893.

Li, Z., Kim, J. K., Chaudhari, V., Mayadevi, S. and Campos, L. C. (2017). Degradation of metaldehyde in water by nanoparticle catalysts and powdered activated carbon. Environmental Science and Pollution Research, 24 (21), 17861-17873. doi: 10.1007/s11356-017-9249-1.

Li, Z., Yang, Y., J'auregui-Haza U., Guo, Z., and Campos, L.C. (2019). The impact of humic acid on metaldehyde adsorption onto powdered activated carbon in aqueous solution. RSC Advances, 9, 11-22. doi.org/10.1039/C8RA06802J

Li, Z., Li, J., Guo, Z. and Campos, L.C. (2020) Investigation of metaldehyde removal by powdered activated carbon from different water samples. Environmental Science: Water Research and Technology, 6, 1432-1444. doi.org/10.1039/C9EW00962K.

Marshal, J. (2013) Briefing paper on metaldehyde, Water UK. Available at: https://www.water.org.uk/sites/default/files/documents/Policy-Briefings/Water 13 Aug 2013_0.pdf.

Matsui, Y., Fukuda, Y., Inoue, T. and Matsushita, T. (2003). Effect of natural organic matter on powdered activated carbon adsorption of trace contaminants: Characteristics and mechanism of competitive adsorption. Water Research, 37(18), 4413-4424. doi.org/10.1016/S0043-1354(03)00423-8.

Rao, N. R., Yap, R., Whittaker, M., Stuetz, R. M., Jefferson, B., Peirson, W. L., Granville, A. M., Henderson, R. K. (2018). The role of algal organic matter in the separation of algae and cyanobacteria using the novel "Posi" - Dissolved air 
flotation

process. Water

Research,

130

20-30.

doi.org/10.1016/j.watres.2017.11.049.

Ribeiro, P. and Daniel, L. A. (2016). Dissolved air flotation as a potential treatment process to remove Giardia cysts from anaerobically treated sewage. Environmental Technology, $\quad 38 \quad$ (19), 2392-2399. doi.org/10.1080/09593330.2016.1262461.

Salvestrini, S., Vanore, P., Bogush, A., Mayadevi, S. and Campos, L. C. (2017). Sorption of metaldehyde using granular activated carbon. Journal of Water Reuse and Desalination, 7 (1), 280-287. doi.org/10.2166/wrd.2016.074

Shutova, Y., Karna, B. L., Hambly, A. C., Lau, B., Henderson, R. K. and Le-Clech, P. (2016). Enhancing organic matter removal in desalination pretreatment systems by application of dissolved air flotation. Desalination, 383, 12-21. doi.org/10.1016/j.desal.2015.12.018.

Tang, L. L., DeNardo, M. A., Gayathri, C., Gil, R. R., Kanda, R. and Collins, T. J. (2016). TAML/ $\mathrm{H}_{2} \mathrm{O}_{2}$ oxidative degradation of metaldehyde: Pursuing better water treatment for the most persistent pollutants. Environmental Science \& Technology, 50 (10), 5261-5268. doi.org/10.1021/acs.est.5b05518.

Tao, B. and Fletcher, A. (2016). Development of a novel dual-stage method for metaldehyde removal from water. Chemical Engineering Journal, 284, 741-749. doi.org/10.1016/j.cej.2015.09.029.

Tomaszewska, M., Mozia, S. and Morawski, A. W. (2004). Removal of organic matter by coagulation enhanced with adsorption on PAC. Desalination, 161(1), 79-87. doi.org/10.1016/S0011-9164(04)90042-2.

US Environmental Protection Agency (2017). Drinking Water Treatability Database. www.tdb.epa.gov/tdb 
Yu, W-Z, Gregory, J., Graham, N. (2016) Regrowth of broken hydroxide flocs: effect of added fluoride. Environmental Science and Technology, 50 (4), 18281833. doi.org/10.1021/acs.est.5b05334.

Wang, D., Wu, R., Jiang, Y., Chow, C. W. K. (2011). Characterization of floc structure and strength: Role of changing shear rates under various coagulation mechanisms. Colloids and Surfaces A Physicochemical and Engineering Aspects 379 (1), 36-42. doi.org/10.1016/j.colsurfa.2010.11.048.

Zijian, L. \& Jennings, A. (2017). Worldwide regulations of standard values of pesticides for human health risk control: A review. International Journal of Environmental Research and Public Health, 14, 826. doi.org/10.3390/ijerph14070826. 